\title{
Design of biomimetic cell-interactive substrates using hyaluronic acid hydrogels with tunable mechanical properties
}

\author{
Emilie Hachet ${ }^{a}$, Hélène Van Den Berghe ${ }^{a}$, Eric Bayma $^{a}$, Marc R. Block $^{b}$, Rachel Auzély-Velty $^{a}$, $^{*}$ \\ ${ }^{a}$ Centre de Recherches sur les Macromolécules Végétales (CERMAV-CNRS), affiliated with \\ Université Joseph Fourier, 601 rue de la Chimie, 38041 Grenoble, France \\ ${ }^{\mathrm{b}}$ Institut Albert Bonniot, CR INSERM U823; Equipe DySAD (ERL CNRS 5284); Université Joseph \\ Fourier, 38042 Grenoble, France
}

\section{*Corresponding author \\ Tel: +334 760376 71. E-mail: $\underline{\text { rachel.auzely@ cermav.cnrs.fr }}$}

\begin{abstract}
:
Hyaluronic acid (HA) is a natural polysaccharide abundant in biological tissues with excellent potential for constructing synthetic extracellular matrix analogs. In this work, we established a simple and robust/reliable approach to prepare hyaluronic acid-based hydrogels with controlled stiffness and cell recognition properties for use as cell-interactive substrates. This approach relied on a new procedure for the synthesis of methacrylate-modified HA macromers (HA-MA) and, on photorheometry allowing to monitor gelation by photopolymerization. We showed in this way the ability to obtain gels that encompass the range of physiologically relevant moduli while maintaining the recognition properties of HA by specific cell surface receptors. These hydrogels were prepared from HA macromers having a degree of methacrylation in the range of $0.1-0.28$, allowing to minimize compromising effects on the
\end{abstract}


binding affinity of HA to its cell receptors due to high substitution on one hand, and to achieve nearly $100 \%$ conversion of the methacrylate groups on the other. When the HA hydrogels were immobilized on glass substrates, we thus showed that attachment and spreading of a variety of mammalian cells rely on CD44 and its coreceptor RHAMM and can be modulated by the elastic properties of the HA matrix. All together, these results highlight the potential of these HA hydrogel systems and the needs of controlling their chemical and physical properties for applications in cell culture and tissue engineering.

\section{INTRODUCTION}

Matrix elasticity or stiffness has been recently shown to have a dramatic effect on many aspects of cell function including adhesion, migration, proliferation and differentiation. In many cases, cells appear to have a preferred substrate stiffness which correlates well with that of the tissue environment from which they are derived. ${ }^{1-5}$ In order to mimic native tissue architecture for applications in biotechnology and tissue engineering, various polymer scaffolds have been developed as substitute of the body's natural extracellular matrix (ECM). ${ }^{6-7}$ Among these, hydrogels are highly attractive for developing synthetic ECM analogs due to their ability to simulate the microenvironment of most soft tissues. These threedimensional networks made of cross-linked polymer chains possess high water contents allowing for easy solute transport. Furthermore, many hydrogels can be formed under mild, biocompatible conditions and can be straightforwardly modified to exhibit specific cell adhesion ligands, desired elasticity, and degradability. ${ }^{8}$ As it is now well established that the cell microenvironment plays a crucial role in cell physiology and fate, the needs for hydrogels with tunable mechanical properties that can be optimally fitted for a wide variety of cell cultures are becoming more apparent, along with identifying the essential biochemical signals to incorporate into these synthetic ECM analogs. .

Hyaluronic acid (HA) is a natural glycosaminoglycan that is composed of the repeating disaccharide unit of D-glucuronic acid and $N$-acetyl-D-glucosamine. This polysaccharide exists in human and animal tissues as the major component of ECMs, particularly in synovial fluid and the vitreous body of the eye, 
and plays an important role in many biological processes including cell proliferation, cell differentiation, morphogenesis, inflammation, and wound repair. ${ }^{10-13}$ Although not completely understood, the bioactive properties of HA originate from its capacity of specifically interacting with membrane receptors present on most mammalian cells (such as CD44 or RHAMM), ${ }^{14-16}$ as well as with dedicated soluble ECM proteins (named hyaladherins). ${ }^{17-18}$ Due to its unique viscoelastic and biological properties HA finds many biomedical applications such as ophthalmological surgery, treatment of osteoarthritis of the knee, prevention of post-surgical adhesion... ${ }^{19-20}$ In addition, HA has excellent potential for constructing synthetic ECM analogs. ${ }^{21}$ However, chemical modification of HA is required to prepare covalently cross-linked hydrogels and to modulate in vivo degradation rates and cell attachment abilities of the resulting biomaterials. An effective strategy for cross-linking HA under mild conditions is photopolymerization of pendent methacrylates, previously introduced through functionalization of the hydroxyl ${ }^{11,22-31}$ or carboxyl $^{32-33}$ groups of HA. This methodology provides some advantages such as increased spatial and temporal control over crosslinking and biocompatibility with in situ polymerization. ${ }^{34-35}$

Among these photopolymerizable HA derivatives, most of them have resulted in hydrogels with low crosslinking density due to low degrees of methacrylation $(\mathrm{DM} \leq 0.3)$. In order to extend applications of such HA hydrogels, Bencherif et al. recently proposed a new method to prepare HA-methacrylate conjugates with a broader range of DM (from 0.14 to 0.9 ). ${ }^{22}$ In vitro studies of myoblast cell adhesion indicated that the resulting hydrogels possessing various crosslinking densities do not support alone cell spreading as previously reported for fibroblast and endothelial cells. ${ }^{25,33,36}$ When functionalized with the GRGDS peptide, a consensus sequence found in various ECM proteins that trigger the interaction with integrin family cell surface receptors, the hydrogels promoted cell interactions but the degree of methacrylation had a minimal effect on myoblast cell attachment, spreading and proliferation. On the other hand, by using a HA macromer with $100 \%$ modification of the hydroxyl groups and varying the methacrylate consumption through a dual cross-linking method, Marklein et al. demonstrated the ability 
to control stem cell spreading and proliferation on HA hydrogels modified with RGD adhesion moieties. ${ }^{37}$ These latter findings indicate that the mechanical properties of functionalized HA gels can impact some cell types in terms of morphology and functions. As a result, they underscore the importance of fine-tuning gel strength in a broad range of network cross-linking density in order to trigger specific changes in cellular responses. Yet, beside integrin engagement through RGD peptides, as the HA-cell receptor interaction is critically dependent on the molecular weight and conformational freedom of HA, care must be taken regarding the conditions for its chemical cross-linking. Indeed, if the aim is to additionally exploit its biological potential, it must be taken into account that HA interactions with cell surface receptors require minimum sequences of HA repeating units (REF Morra). Thus, HA, which is three HA disaccharide units, is the minimum size of HA chain required to occupy the CD44 binding site, and $\mathrm{HA}_{10}$ or greater is the optimal length (Ref Morra + tammi). TIndeed it has already reported that the degree of substitution of modified HA have an impact on its biological activity. Ref Oh In this study, we aimed to establish a simple and reliable methodology for the synthesis of hyaluronic acid-based hydrogels that encompass the range of physiologically relevant moduli while maintaining binding affinity to HA receptors as biomimetic ECM platforms for cell culture and other tissue engineering applications.

To this end, we first developed new conditions for the methacrylation of HA based on its reaction with methacrylic anhydride, allowing us to prepare in a short time a series of macromer precursors with a large range of DM. Photo-rheometric measurements were then used to monitor in situ gelation of methacrylated HA derivatives under various photopolymerization conditions, including the concentration of the photoinitiator, light intensity, concentration of macromer and, degree of methacrylation. This in-depth rheological study allowed us to define the optimal conditions to prepare hydrogels with a broad range of elastic moduli. Lastly, we determined the effect of HA material rigidity on the attachment and spreading of different cell types. All the cell type tested had the ability to interact with these HA hydrogels. Surprisingly, cell spread on these substrates in a manner that was dependent 
on the hydrogel storage modulus. Using pre-osteoblasts, we determined that attachment and spreading were specifically triggered by both CD44 and its coreceptor RHAMM, the two major cell receptors of HA at the plasma membrane.

\section{MATERIALS AND METHODS}

Materials. Hyaluronic acid $\left(\mathrm{M}_{\mathrm{w}}=100000 \mathrm{~g} / \mathrm{mol}\right)$ was purchased from Lifecore (USA). Methacrylic anhydride (AMA), N,N-dimethylformamide (DMF), phosphate buffer saline (PBS, pH 7.4), (3aminopropyl)trimethoxysilane (APTS, ODTS), hyaluronidase (HAse type VIII, 300 units/mg, ref H3757) were purchased from Sigma-Aldrich-Fluka (L'isle d'Abeau, France). 2-hydroxy-1-[4-(2hydroxyethoxy)phenyl]-2-methyl-1-propanone (Irgacure 2959) was kindly provided by Ciba Specialty Chemicals (Basel, Switzerland). All chemicals were used without any further purification. The water used in all experiments was purified by a Elga Purelab purification system, with a resistivity of 18.2 $\mathrm{M} \Omega \mathrm{cm}$.

Synthesis of methacrylated HA (HA-MA). Hyaluronic acid was derivatized with methacrylic anhydride either in water as reported elsewhere ${ }^{28}$ or, in a mixture of water/DMF $(1 / 1, \mathrm{v} / \mathrm{v})$. In the following, we describe the latter procedure which was optimized in this work and allowed us to obtain HA-MA derivatives with higher DM.

HA $(0.20 \mathrm{~g}, 0.50 \mathrm{mmol})$ was dissolved in ultrapure water $(10 \mathrm{~mL})$ at $4{ }^{\circ} \mathrm{C}$ and the resulting mixture was kept at $4{ }^{\circ} \mathrm{C}$ under continuous stirring overnight for complete dissolution. DMF $(6.7 \mathrm{~mL})$ was then added dropwise in order to have a water/DMF ratio of $(3 / 2$, v/v). AMA $(0.5,1,2$ or 3 molar equivalents with respect to the moles of repeating unit of HA, i.e. $0.039 \mathrm{~g}(0.25 \mathrm{mmol}), 0.077 \mathrm{~g}(0.5 \mathrm{mmol}), 0.154 \mathrm{~g}$ (1 mmol) or $0.231 \mathrm{~g}(1.5 \mathrm{mmol})$, respectively) was added while maintaining the $\mathrm{pH}$ between 8 and 9 (by adding $0.5 \mathrm{M} \mathrm{NaOH}$ ) for 4 hours. The reaction was kept at $4{ }^{\circ} \mathrm{C}$ under continuous stirring for one night. After this time, $\mathrm{NaCl}$ was added to the reaction mixture to have a $\mathrm{NaCl}$ concentration of $0.5 \mathrm{M}$. The polymer was precipitated by addition of ethanol (with a water/ $\mathrm{EtOH}(\mathrm{v} / \mathrm{v}$ ) ratio of 2/3). After removal 
of the supernatant, the precipitate was successively washed with mixtures of water/EtOH $(3 / 7,1 / 4,1 / 9$, $\mathrm{v} / \mathrm{v}$ ) and finally dissolved in ultrapure water for a final purification by diafiltration (ultramembrane Amicon YM10) with ultrapure water. The purified product was recovered by freeze-drying and characterized by ${ }^{1} \mathrm{H}$ NMR spectroscopy (Supporting Information, Figure SI-1).

Characterization of methacrylated HA by ${ }^{1} \mathbf{H}$ NMR. ${ }^{1} \mathrm{H}$ NMR spectra of the HA-MA derivatives dissolved in deuterium oxide $(6 \mathrm{mg} / \mathrm{mL})$ were performed at $80{ }^{\circ} \mathrm{C}$ using a Bruker DRX400 spectrometer operating at $400 \mathrm{MHz}$. Deuterium oxide was obtained from SDS (Vitry, France). All spectra were recorded by applying a $45^{\circ}$ tip angle for the excitation pulse, and a 10 s recycle delay for 128 scans. The DM of the samples was determined by digital integration of the anomeric protons signals or methyl protons signals of HA and of the methacrylate proton signals at $\sim 6.1, \sim 5.7$ and $\sim 1.9 \mathrm{ppm}$.

Rheometry. An AR2000Ex rheometer (TA Instruments Inc.) fitted with a UV-curing cell $(\lambda=365 \mathrm{~nm})$ and an aluminum plate (diameter $20 \mathrm{~mm}$ ) was used for the in situ measurement of the viscoelastic properties of the HA-methacrylate gels. Following deposition of $250 \mu \mathrm{L}$ of HA-MA solution, the gap between the flat quartz plate and the aluminum plate was initially $0.7 \mathrm{~mm}$ (measuring ambient temperature). It was controlled during the experiments by maintaining the normal force at $0 \pm 0.1 \mathrm{~N}$. During oscillatory time sweep tests, drops of the $G^{\prime}$ modulus were observed a few min $(\sim 5-10$ min $)$ after its sharp increase (as a result of network formation) for the hydrogels with high stiffness. These were attributed to grip-slip caused by the release of water from the hydrogels. Therefore, the flat quartz plate was sanded, which allowed us to overcome this experimental problem (Supporting Information, Figure SI-2). It should be noted that the treatment of the quartz plate had no effect on the values of both moduli (Supporting Information, Figure SI-3).

On each hydrogel of methacrylated HA, oscillatory time sweep and frequency sweep experiments were performed. All the dynamic rheological data were checked as a function of strain amplitude to ensure that the measurements were performed in the linear viscoelastic region.

In the oscillatory time sweep experiments, the storage modulus (G') and loss modulus (G') were 
measured during a period of $23 \mathrm{~min}$ or $43 \mathrm{~min}$ (depending on the macromer concentration) at a fixed frequency of $1 \mathrm{~Hz}$ and a fixed deformation of $3.5 \%$. Typically, after deposition of the solution of methacrylated HA in PBS between the plates and equilibration for 1 min $30 \mathrm{~s}$, the solution was illuminated $(\lambda=365 \mathrm{~nm})$ for $20 \mathrm{~min}$ or $40 \mathrm{~min}$ at a fixed light power $\left(50 \mathrm{~mW} / \mathrm{cm}^{2}\right.$ in most of experiments) leading to gelation. Light illumination was then stopped for 1 min $30 \mathrm{~s}$. All measurements were done in triplicate.

Enzymatic degradation of hydrogels. Hydrogel disks ( $0.7 \mathrm{~mm}$ thickness, $20 \mathrm{~mm}$ diameter $)$ prepared by photopolymerization of solutions of HA-MA were immersed into PBS (2 mL) containing $500 \mathrm{U}$ hyaluronidase per $\mathrm{mL}$. The degradation was carried out at $37{ }^{\circ} \mathrm{C}$ for $20 \mathrm{~h}$, then $95{ }^{\circ} \mathrm{C}$ for $20 \mathrm{~min}$. The resulting solutions were freeze-dried and analyzed by ${ }^{1} \mathrm{H} \mathrm{NMR}$ at $25{ }^{\circ} \mathrm{C}$ after solubilization in deuterium oxide to determine if unreacted methacrylate groups were present.

Hydrogel immobilization. For the cell culture experiments, hydrogels were covalently linked to a coverslip during photopolymerization by methacrylation of the coverslip prior to use. The methacrylated coverslip was prepared by treating the slip previously modified with ODTS/APTS with methacrylic anhydride. The glass slip was modified with a mixture of ODTS and APTS as previously described. ${ }^{38}$ Briefly, the modified slip with $-\mathrm{NH}_{2}$ groups was immersed in PBS $(5 \mathrm{~mL})$ containing AMA $(0.1 \mathrm{~mL})$ and stirred at room temperature for half a day. The slip was then rinsed by EtOH/water (1/1, v/v) mixtures, water and dried in air before use. HA-MA solutions, deposited on the non-sanded quartz plate of the rheometer, were gelled in contact with the methacrylated glass coverslips. Under such conditions, hydrogels with different stiffness (G' modulus varying from 600 to $17000 \mathrm{~Pa}$ ) were prepared. After preparation, hydrogels were transferred to cell culture media (Dulbecco's modified minimal essential medium, DMEM, Invitrogen) supplemented with $50 \mathrm{U} / \mathrm{mL}$ penicillin, and $50 \mathrm{mg} / \mathrm{mL}$ streptomycin and left for $12 \mathrm{~h}$ for equilibrium before cell culture studies. Media was refreshed after $12 \mathrm{~h}$ to remove any remaining monomer or initiator.

Cell culture and biological reagents. NIH-3T3L was a subclone of ATCC NIH3T3 selected for its 
high spreading ability and HeLa cells were from ATCC and grown in aMEM and DMEM respectively, supplemented with $10 \%$ fetal calf serum and antibiotics in a humidified $5 \% \mathrm{CO}_{2}$ atmosphere. Primary osteoblasts (passage 2) were immortalized by transduction with a retrovirus expressing the large SV40 T antigen, ${ }^{39}$ cloned, and tested for their ability to express alkaline phophatase upon differentiation, ${ }^{40}$ as previously described $^{41}$. They were cultivated under the standard conditions in DMEM supplemented in $10 \%$ fetal calf serum. Blocking HA receptors CD44 and RHAMM were from Beckton Dinkinson (Le Pont de Claix, France) and Santa Cruz Technologies (Tebu Bio, Le Perray en Yvelines France), respectively, and the toxic preservative $\mathrm{NaN}_{3}$ was removed by spin desalting prior to use.

Cell labeling and quantification of cell spreading. For quantifying the projected areas of spread cells, the cells were fixed 10 min with a solution of $4 \%(\mathrm{w} / \mathrm{v})$ of paraformaldehyde in $0.2 \mathrm{M}$ phosphate buffer $(\mathrm{pH}=7.2)$ for $10 \mathrm{~min}$ at room temperature. After 3 washes in PBS, the cells were incubated in DMEM supplemented with $0.5 \%$ of Vybrant ${ }^{\mathrm{TM}}$ DIL cell labeling solution for $15 \mathrm{~min}$ at $37^{\circ} \mathrm{C}$ according to the manufacturer (Life Technologies, St Aubin, France). The cells were washed 3 times in PBS and mounted under a coverslip with $10 \mu \mathrm{L}$ of mounting solution for epifluorescence observations. Observation were carried out with a Provis 70 microscope (Olympus Europe Hamburg, Germany) equipped with a Plan NeoFluar 20X (N.A. 0.5) objective. Areas were determined with Metamorph software (Molecular Devices, Sunyvale, CA USA) at a magnification of 200X. Statistical analyses were carried out with R software (The R Project for Statistical Computing, http://www.r-project.org/)

\section{RESULTS AND DISCUSSION}

Synthesis of HA-methacrylate macromers. Several methods have been developed for synthesizing methacrylate-modified HA, some of them using methacrylic anhydride ${ }^{23,28-30}$ and others glycidyl methacrylate $(\mathrm{GMA})^{11,24-27,31,42}$. In both cases, the degree of methacrylation did not exceed 0.3 when methacrylation was performed in aqueous solution due in part to the low solubility and hydrolysis of AMA and GMA in water. Therefore, in order to enhance the DM, alternative methods consisting of the 
reaction of HA with GMA in organic solution or in a hydro-organic mixture were developed. ${ }^{22,} 27$ Bencherif et al. showed the ability to increase the DM up to 0.9 when the reaction of HA with GMA was performed in a water/DMF mixture at physiological $\mathrm{pH}$ but it required a long reaction time (10 days). ${ }^{22}$ Different esters resulting from a reversible transesterification through the primary hydroxyl group and an irreversible ring-opening conjugation through the carboxylic acid group toward the highest substituted carbon of epoxide were assumed to be formed simultaneously. Their respective amounts were reported to be time-dependent, the concentration of ring-opening products thus increasing with time.

In this work, we synthesized methacrylated HA derivatives by reaction of methacrylic anhydride with the hydroxyl groups of HA, leading to only one type of ester (Figure SI-1).

As previously reported, ${ }^{23,28,30}$ when the reaction of AMA with native HA was performed in aqueous solution, we obtained HA derivatives with low DM $(\leq 0.20)$ although AMA was added in large excess (see Table 1). By comparing the molar ratio of AMA to HA in the reaction medium and the DM of modified HA, it can be noticed that for the two feed ratios, HA was derivatized with 1-5\% of the added AMA. Interestingly, the degree of methacrylation could be enhanced by using DMF as co-solvent and the percentage of derivatization of HA for the four feed ratios was between 16 and $24 \%$ of the added AMA after $16 \mathrm{~h}$ of reaction (Table 1). Actually, such conditions allow the solubilization of methacrylic anhydride in the reaction medium resulting in better control over the DM. This method compared favorably with that performed with GMA in PBS/DMF ${ }^{22}$ which required much longer reaction times (510 days) and higher GMA/HA molar ratios (with respect to the AMA/HA ratios) to obtain DM in the range of $0.32-0.60$.

Hydrogel formation and rheological properties. The gels were formed by photopolymerization at 365 nm of HA-MA macromers in the presence of photoinitiator Irgacure 2959 which was selected for its known biocompatibility with cells. ${ }^{43}$ The gelation process was monitored in situ by photorheometry. In order to optimize the conditions for the synthesis of HA networks, we investigated the effect of various 
experimental parameters that control photogelation, i.e. photoinitiator concentration and power of light used for irradiation. Figure 1 shows the effect of (A) photoinitiator concentration and, (B) power of light used for irradiation on the time sweep profiles of the storage modulus $\left(G^{\prime}\right)$ and loss modulus (G', obtained from a solution of HA-MA $\mathbf{2 b}$ with a DM of 0.20 .

The samples were equilibrated for $1 \mathrm{~min} 30 \mathrm{~s}$ before being illuminated for a time of 20 or $40 \mathrm{~min}$ (see Materials and Methods). Initially, G', is larger than $\mathrm{G}^{\prime}$, reflecting the viscous behavior of the sample. After an induction period, which depends on the photoinitiator concentration and power of light, the storage modulus increases sharply due to the formation of elastic effective intermolecular cross-links whereas the loss modulus increased negligibly during this time. Consequently, there is a cross-over point where G' becomes higher than G', The time required for this crossover to occur is sometimes referred to as the gelation time although this point depends on the applied frequency. ${ }^{44-45}$ In the postgelation period, the G' curve levels off indicating the end of the gelation process. In this context, the steady-state value of $\mathrm{G}^{\prime}$ was used as a metric for hydrogel elasticity. The loss modulus increased negligibly during this time for all hydrogels.

From Figure 1A, it can be seen that the time required for the beginning of gelation, corresponding to the time where $G^{\prime}$ becomes equal to $G^{\prime \prime}$ as mentioned above, is dependent on the photoinitiator concentration. In these experiments, the power of light used for irradiation was fixed at $50 \mathrm{~mW} / \mathrm{cm}^{2}$. For concentrations in the range of $0.05-0.2 \%(w / v$, i.e. [photoinitiator]/[MA] ratios ranging from 0.30 to 1.23), the gelation times are around $2 \mathrm{~min} 40 \mathrm{~s}$. However, when the initiator concentration was decreased to $0.025 \%$ or lower, one can notice significant increase in the gelation time going from 3 min $20 \mathrm{~s}$ for the concentration of $0.025 \%$ (i.e. a [photoinitiator]/[MA] ratio of 0.15 ) to $6 \mathrm{~min} 30 \mathrm{~s}$ for a concentration of $0.01 \%([$ photoinitiator $] /[\mathrm{MA}]$ ratio $=0.06)$. Moreover, a significant decrease in the G' modulus can be observed for the latter two concentrations. For the lowest initiator concentration, the G' modulus thus tends to a value which is $\sim 10$ times lower than those measured for the three higher concentrations. This suggests that the initial photoiniator concentration is too low to activate all 
methacrylate groups for radical polymerization. The activation of the methacrylate groups is particularly delicate as it strongly depends on the diffusion of the photoiniator in the HA chemical network. On the other hand, the slight decrease in the G' values with the time observed for the higher concentrations may be related to the slight degradation of HA network due to the high concentration of radicals produced by the photoinitiator. Indeed, the same experiment performed with a film of silicone oil lead to a similar curve indicating almost no solvent evaporation during the experiment performed under these conditions (Supporting Information, Figure SI-4). All together, these data suggest that below a critical [photoinitiator]/[MA] ratio situated between 0.06 and 0.15 , the completion of network formation requires much longer times of irradiation.

The decrease in the light power from 144 to $15 \mathrm{~mW} / \mathrm{cm}^{2}$ also delayed the beginning of gelation whereas it did not have striking effect on the steady-state value of G' (Figure 1B). As can be seen on Figure 1B, the time required for the G' modulus to reach a plateau was significantly increased when the light power was decreased to $15 \mathrm{~mW} / \mathrm{cm}^{2}$. Indeed, the G' modulus was found to level off after 40 min of irradiation, whereas the steady-state value of G' was reached after $\sim 20$ min of irradiation for light powers $>50$ $\mathrm{mW} / \mathrm{cm}^{2}$. Therefore, from these results, all subsequent oscillatory time sweep experiments were performed using a photoinitiator concentration of $0.05 \%$ and a light power of $50 \mathrm{~mW} / \mathrm{cm}^{2}$. One can notice a progressive decrease of the G' modulus after reaching its maximum for the sample illuminated with UV light at a power of $144 \mathrm{~mW} / \mathrm{cm}^{2}$. Such conditions likely result in sample heating, causing partial evaporation of water. Indeed, when the same experiment was carried out with a film of silicone oil, the decrease was much less pronounced (Supporting Information, Figure SI-5). This result supports our hypothesis that almost no solvent evaporation occurs when polymerizations are conducted with UV light at a power of $50 \mathrm{~mW} / \mathrm{cm}^{2}$.

We next focused our attention on some factors that may affect mechanical strength, namely macromer concentration and degree of methacrylation.

Figure 2 shows the influence of time of irradiation and macromer concentration on the storage modulus 
of hydrogels prepared from the derivatives $\mathbf{2 a}$ and $\mathbf{2 b}$. As can be seen from this Figure, while the G' values become constant $\sim 20 \mathrm{~min}$ after the beginning of irradiation (i.e. $21 \mathrm{~min} 30 \mathrm{~s}$ after the beginning of the oscillatory shear experiment) for the hydrogels made from the macromer $\mathbf{2 a}$ whatever its concentration, it appears that for the hydrogel prepared from $\mathbf{2 b}$ at a macromer concentration of $50 \mathrm{~g} / \mathrm{L}$, the $G^{\prime}$ values level off only $~ 35$ min after the beginning of experiment. Moreover, a similar behavior to 2b was observed for HA-MA 2c. These results indicate that from DS values $\geq 0.2$ and macromer concentrations $\geq 50 \mathrm{~g} / \mathrm{L}$, the time of irradiation performed using a photoinitiator concentration of $0.05 \%$ must be increased from $\sim 20$ min to $\sim 40$ min to reach a plateau for G'. It should be noted that in the case of $\mathbf{2 b}$, this time could be decreased to $\sim 30$ min by increasing two fold the photoinitiator concentration. However, the steady-state value of $\mathrm{G}^{\prime}$ was found to be $20 \%$ lower than that obtained with a photoinitiator concentration of $0.05 \%$, which was attributed to degradation of HA at high radical concentrations.

To verify if the time for $G^{\prime}$ to level off corresponds to the total conversion of the methacrylate groups, we analyzed by ${ }^{1} \mathrm{H}$ NMR samples of HA-MA $2 \mathbf{b}\left(C_{p}=50 \mathrm{~g} / \mathrm{L}\right)$ which were photopolymerized for 20 and $40 \mathrm{~min}$ and subsequently degraded by hyaluronidase. After $20 \mathrm{~h}$ incubation at $37{ }^{\circ} \mathrm{C}$ in $500 \mathrm{U}$ hyaluronidase $/ \mathrm{mL}$, the swollen networks were converted into solutions due to the cleavage of internal $\beta$ $N$-acetyl-D-glucosaminidic linkages in HA chains. After 20 and 40 min of irradiation, traces of methacrylate double bonds could be observed from the NMR spectra (Supporting Information, Figure SI-6). Digital integration of the proton signals of the double bonds and the anomeric proton signals of HA indicated that increasing time of irradiation from 20 to $40 \mathrm{~min}$ lead to an increase in the crosslinking conversion from 80 to $90 \%$. This result suggests that the time required for $\mathrm{G}^{\prime}$ to become nearly constant can be considered as an indication of the time for the photopolymerization to reach near $100 \%$ conversion. This method can have some advantages compared to ${ }^{1} \mathrm{H}$ NMR analysis considering its simplicity, rapidity and sensitivity. It should be noted that Fourier Transform Infrared spectroscopy failed to reveal traces of methacrylate double bonds in the sample. The fact that $100 \%$ conversion is not 
strictly obtained can be attributed to severe mobility restrictions after the gel point is reached, which hamper reactions between all methacrylate groups especially when their concentration is very high as discussed below.

Comparing HA-MA hydrogels prepared from solutions of macromers at the same concentration (15 $\mathrm{g} / \mathrm{L}$ ) but with different $\mathrm{DM}$, an increase in the storage modulus values measured 21 min after the beginning of irradiation could be observed as the DM of macromers was increased from 0.12 to 0.28 (Figure 3). This is consistent with theory which predicts that for crosslinked rubberlike networks, the elasticity is related to the concentration of crosslinks by the relation

$$
\mathrm{G}=n \mathrm{RT} / \mathrm{V}
$$

Where $n$ is the number of moles of elastic chains per volume $\mathrm{V}$, and $\mathrm{R}$ is the gas constant. ${ }^{46}$ It should be noted however, that in this work, $n$ cannot be directly related to the DM of HA macromers owing to the complexity of the network structure consisting of HA chains cross-linked by oligo(methacrylate) chains. A lower storage modulus value was found when the DM reached 0.49. As such DM means that on average one over two repeating units is substituted by a methacrylate group, it can be reasonably assumed that the $100 \%$ conversation of methacrylate groups is hindered by accessibility problems due to the high DM and severe mobility restrictions after the gel point is reached. This assumption was supported by other experiments performed at higher macromer concentrations which afforded hydrogels with significantly lower storage modulus values compared to those of hydrogels prepared from the derivatives 2a-c as well as ${ }^{1} \mathrm{H}$ NMR analysis of hydrogels after degradation by hyaluronidase. Indeed, signals corresponding to the protons of methacrylate double bonds could be observed from the NMR spectra of samples prepared from $2 \mathrm{c}$ at concentrations of 15 and $30 \mathrm{~g} / \mathrm{L}$ (Supporting Information, Figure SI-7). Digital integration of these signals and the anomeric proton signals of HA indicated cross-linking conversions of 82 and $61 \%$ for gels made at macromer concentrations of 15 and $30 \mathrm{~g} / \mathrm{L}$, respectively. In order to determine conditions to prepare gels in the physiologically relevant stiffness, we then compared the evolution of $G^{\prime}$ by varying the concentration of macromers 2a-c. Matrix elasticity can 
vary from 100 to a few thousands $\mathrm{Pa}$ depending on the natural tissue. ${ }^{5,47}$ Figure 4 plots the storage modulus as a function of methacrylate concentration $\left(C_{M A}\right.$, calculated from the average molar mass of the repeating unit of HA-MA and the DM) for hydrogels made from solutions of HA-MA 2a-c as well as a HA-MA derivative (1b) prepared according to a literature procedure ${ }^{28}$ at concentrations in the range 15-50 g/L. As can be seen on this Figure, a large range of physiologically relevant stiffness can be produced from solutions of HA-MA derivatives with DM between 0.12 and 0.28 . Interestingly, a unique curve is obtained for $C_{M A}$ ranging from $4.4 \times 10^{-3} \mathrm{~mol} / \mathrm{L}$ to $\sim 20 \times 10^{-3} \mathrm{~mol} / \mathrm{L}$, thus indicating that HA macromers 1b, 2a-c can independently be used for preparing hydrogels having well-defined storagemoduli included between 500 and $21000 \mathrm{~Pa}$. All together, these results demonstrate that thanks to optimized procedures for the synthesis of HA-MA derivatives and their photopolymerization, hydrogels with tunable stiffness could be prepared with good reproducibility by varying the DM or macromer concentration.

Cellular responses in vitro. Next, we wanted to check the ability of mammalian cells to interact with our methacrylated HA hydrogels. In order to provide stability during manipulation and experimentation with cells, the hydrogels were immobilized to glass substrates during their synthesis by photopolymerization under the optimal conditions discussed above. Therefore, from the unique curve depicted in Figure 4, several macromer solutions were prepared, deposited on the non-sanded quartz plate of the rheometer and were gelled in contact with glass coverslips modified with methacrylate units. Three different cell lines were subsequently seeded on the hydrogels as described under Materials and Methods and cultivated overnight in DMEM under standard conditions. Figure 5 shows that under these experimental conditions, the different cell types were able to adhere firmly on the hydrogels and were no longer floating in the medium. Surprisingly, all cell types were able to spread to various degrees onto these substrates in a manner that was dependent on the storage modulus in a very similar way that was observed in the classical integrin mediated adhesion to ECM proteins, i.e., favored by the increase in the storage modulus. ${ }^{48}$ 
Cell spreading is the read-out of cytoskeleton reorganization and establishment of internal tensions. It was markedly dependent on the cell type. HeLa cells were poorly spread even at the highest storage modulus although some small membrane extensions were occasionally detected at 17000 Pa suggesting some initiation of the spreading process. However the quantification of the distribution of the cell projected areas $(n=60)$ showed that those epithelial cells did respond to the storage modulus although to a lesser extent. Conversely, NIH 3T3L cells were fully spread at this storage modulus and exhibited a polarized morphology suggesting a high motility activity. Finally pre-osteoblast exhibited an intermediate situation with some spreading that was increased from 600 to $17000 \mathrm{~Pa}$. The differences observed according to the cell types suggested that the attachment and spreading observed was not due to some nonspecific binding of adsorbed ECM proteins since all cell types attached and spread similarly on ECM protein coated surfaces (not shown). Cell type dependence also ruled out a possible cell surface interaction with unreacted methacrylate moieties. In addition, trypan blue staining showed a good viability (94\%) of the cell spread on HA methacrylates gels (not shown). It should be noted that no difference was observed by comparing the biological response of HA-MA gels having the same stiffness (2500 Pa) but prepared from different HA-MA samples, i.e. $2 \mathbf{a}(40 \mathrm{~g} / \mathrm{L})$ and $2 \mathbf{d}(15 \mathrm{~g} / \mathrm{L})$, for which the methacrylate conversion after photopolymerization was different ( $100 \%$ for $\mathbf{2 a}$ and $82 \%$ for $\mathbf{2 d}$ ) (Figure SI-8). To confirm that cell behavior on methacrylated HA hydrogels was due to a specific interaction of the cells with $\mathrm{HA}$, we pre-incubated for one hour at $4^{\circ} \mathrm{C}$ pre-osteoblasts with blocking antibodies directed against the two major HA receptors at the concentration of $30 \mu \mathrm{g} / \mathrm{mL}$ Subsequently overnight culture in DMEM containing the antibodies was carried out on HA methacrylate gels.

After 12 hours of culture, the cells were fluorescently labeled with a lipophilic tracer Vybrant ${ }^{\mathrm{TM}}$ DIL as described under Materials and Methods, and the fluorescent cell images were taken using a Provis 70 Olympus inverted microscope.

Figure 6 shows that even at high storage modulus, cell attachment and spreading to HA-MA gels could be almost fully inhibited by adding either anti CD44 or anti RHAMM. It is notworthy that incubation of 
the cells with the antibodies did not affect cell spreading of cell on the culture plastic surrounding the HA gels in the 6 well plates, ruling out a possible toxicity of these antibodies. These results indicated that both receptors were functional on these cells and strongly suggested that cell spreading was due to the interaction of the gel HA moiety with specific receptors and not to interferences with either methacrylate moieties or adsorbed proteins.

\section{CONCLUSIONS}

By improving the synthesis of methacrylated HA based on its reaction with methacrylic anhydride as well as the photopolymerization conditions of the resulting macromers for gel formation by in situ photorheometry measurements, we showed in this work the ability to prepare transparent hydrogels with good reproducibility and a large range of elasticity. Interestingly, by plotting the storage modulus of the hydrogels as a function of the initial concentration of methacrylate functions linked to HA macromers, we obtained a single curve indicating that HA macromers with DM in the range of $0.1-0.30$ can independently be used for the synthesis of HA matrices with storage-moduli included between 500 and $21000 \mathrm{~Pa}$. This result was then exploited to synthesize series of HA hydrogel substrates for 2dimensional cell culture experiments using various cell types. Very interestingly, we showed that the cells not only interacted with the HA hydrogels but were able to spread on these surfaces in a manner that was favored by the increase in the gel rigidity. This interaction was specific and involved on preosteoblast the HA receptors CD44 and RHAMM. Rigidity dependence of integrin mediated cell adhesion through ECM protein has been extensively described and the mechanism of integrin mechanotransduction partly unraveled. However, our data indicated for the first time cell types are sensitive to the substrate rigidity when cells are only using HA receptors indicating that these transmembrane proteins also play a role of mechanotransducers and induced the rearrangement of actin cytoskeleton. Cell interaction with a nonspecific matrix such as poly(L-lysine) results in an isotropic spreading of the

cells and indeed, the initial stage of cell spreading seems to be independent on integrin activation. ${ }^{49}$ 
However in the case of HA hydrogels the final stages of cell spreading was strongly anisotropic with highly polarized cells indicating that HA receptors are likely to engage active processes within the cells that support migration. Other reports have mentioned the lack of cell spreading of human dermal fibroblasts and NIH3T3 cells, respectively. ${ }^{33,36}$ Our data show that cell spreading on HA gels is cell type and storage modulus dependent. In addition for most of the cells, this spreading however is quite smaller than integrin mediated spreading (for instance when hydrogels are functionalized with RGD peptides). Such limited spreading has been neglected in former works. Earlier studies with NIH3T3 cells were carried out in the absence of serum. ${ }^{36}$ These experimental conditions switched off the regulatory GTPase RhoaA and consequently myosin II activity, resulting in the loss of cellular contractility that is required for cell spreading. In summary, HA hydrogels with a large range of mechanical properties seem to be very powerful tools for Cell Biology and provide a microenvironment suitable for a fine tuning of Cell Physiology.

\section{ACKNOWLEDGMENT}

This work was financially supported by the "Agence Nationale pour la Recherche" (grant ANR P3N 2009 to RAV). HVDB gratefully acknowledges the CNRS for a post-doctoral fellowship. RAV is indebted to the Institut Universitaire de France for financial support.

\section{Supporting Information Available:}

${ }^{1} \mathrm{H}$ NMR spectrum of of HA-MA derivatives 2a-d; in situ photorheometric measurement of hydrogel formation from methacrylate modified-HA $2 \mathbf{c}$ performed on a non-sanded and sanded quartz plate; in situ photorheometric measurement of hydrogel formation from methacrylate modified-HA 2b performed on a non-sanded and sanded quartz plate; in situ photorheometric measurement of hydrogel formation from methacrylate modified-HA $\mathbf{2 b}$ performed in the absence and in the presence of a film of 
silicone oil; in situ photorheometric measurement of hydrogel formation from methacrylate modified-

HA $\mathbf{2 b}$ performed in the absence and in the presence of a film of silicone oil; ${ }^{1} \mathrm{H}$ NMR spectra of initial

HA and HA-MA hydrogels after digestion by hyaluronidase; ${ }^{1} \mathrm{H}$ NMR spectra of hydrogels prepared from HA-MA 2d at $15 \mathrm{~g} / \mathrm{L}$ and $30 \mathrm{~g} / \mathrm{L}$ in PBS after digestion by hyaluronidase; pre osteoblast spreading on HA-MA gels with a storage modulus of 2500 Pa prepared with HA-MA 2a (40 g/L) and HA-MA 2d $(15 \mathrm{~g} / \mathrm{L})$. This material is available free of charge via the Internet at http://pubs.acs.org.

\section{REFERENCES}

1. Discher, D. E.; Janmey, P.; Wang, Y.-1. Science 2005, 310, 1139-1143.

2. Engler, A. J.; Sen, S.; Sweeney, H. L.; Discher, D. E. Cell 2006, 126, 677-689.

3. Ghosh, K.; Ingber, D. E. Adv. Drug Delivery Rev. 2007, 59, 1306-1318.

4. Paszek, M. J.; Zahir, N.; Johnson, K. R.; Lakins, J. N.; Rozenberg, G. I.; Gefen, A.; Reinhart-King, C. A.; Margulies, S. S.; Dembo, M.; Boettiger, D.; Hammer, D. A.; Weaver, V. M. Cancer Cell 2005, 8, 241-254.

5. Yeung, T.; Georges Penelope, C.; Flanagan Lisa, A.; Marg, B.; Ortiz, M.; Funaki, M.; Zahir, N.; Ming, W.; Weaver, V.; Janmey Paul, A. Cell Motil Cytoskeleton 2005, 60, 24-34.

6. Patterson, J.; Martino, M. M.; Hubbell, J. A. materialstoday 2010, 13, 14-22.

7. Tibbitt, M. W.; Anseth, K. S. Biotechnology and Bioengineering 2009, 103, 655-662.

8. Lutolf, M. P.; Hubbell, J. A. Nat. Biotechnol. 2005, 23, 47-55.

9. Kloxin, A. M.; Kloxin, C. J.; Bowman, C. N.; Anseth, K. S. Adv. Mater. 2010, 22, 3484-3494.

10. Chen, W. Y. J. Hyaluronan, 12th 2002, 2, 147-156.

11. Jia, X.; Burdick, J. A.; Kobler, J.; Clifton, R. J.; Rosowski, J. J.; Zeitels, S. M.; Langer, R. Macromolecules 2004, 37, 3239-3248.

12. Takahashi, Y.; Li, L.; Kamiryo, M.; Asteriou, T.; Moustakas, A.; Yamashita, H.; Heldin, P. J. Biol. Chem. 2005, 280, 24195-24204.

13. Toole, B. P. Semin. Cell Dev. Biol. 2001, 12, 79-87.

14. Entwistle, J.; Hall, C. L.; Turley, E. A. J Cell Biochem 1996, 61, 569-77.

15. Peach, R. J.; Hollenbaugh, D.; Stamenkovic, I.; Aruffo, A. J. Cell Biol. 1993, 122, 257-64.

16. Yang, B.; Zhang, L.; Turley, E. A. J. Biol. Chem. 1993, 268, 8617-23.

17. Day, A. J.; de la Motte, C. A. Trends Immunol. 2005, 26, 637-643.

18. Day, A. J.; Sheehan, J. K. Curr. Opin. Struct. Biol. 2001, 11, 617-622.

19. Kogan, G.; Soltes, L.; Stern, R.; Gemeiner, P. Biotechnol. Lett. 2007, 29, 17-25.

20. Prestwich, G. D.; Kuo, J.-w. Curr. Pharm. Biotechnol. 2008, 9, 242-245.

21. Burdick, J. A.; Prestwich, G. D. Adv. Mater. 2011, 23, H41-H56.

22. Bencherif, S. A.; Srinivasan, A.; Horkay, F.; Hollinger, J. O.; Matyjaszewski, K.; Washburn, N. R. Biomaterials 2008, 29, 1739-1749.

23. Burdick, J. A.; Chung, C.; Jia, X.; Randolph, M. A.; Langer, R. Biomacromolecules 2005, 6, 386391.

24. Jin, Y.; Yamanaka, J.; Sato, S.; Miyata, I.; Yomota, C.; Yonese, M. J. Controlled Release 2001, 73, 173-181.

25. Leach, J. B.; Bivens, K. A.; Collins, C. N.; Schmidt, C. E. J. Biomed. Mater. Res., Part A 2004, 
70A, 74-82.

26. Leach, J. B.; Bivens, K. A.; Patrick, C. W., Jr.; Schmidt, C. E. Biotechnol. Bioeng. 2003, 82, 578589.

27. Oudshoorn, M. H. M.; Rissmann, R.; Bouwstra, J. A.; Hennink, W. E. Polymer 2007, 48, $1915-$ 1920.

28. Pitarresi, G.; Pierro, P.; Palumbo, F. S.; Tripodo, G.; Giammona, G. Biomacromolecules 2006, 7, 1302-1310.

29. Shah, D. N.; Recktenwall-Work, S. M.; Anseth, K. S. Biomaterials 2008, 29, 2060-2072.

30. Smeds, K. A.; Pfister-Serres, A.; Miki, D.; Dastgheib, K.; Inoue, M.; Hatchell, D. L.; Grinstaff, M. W. J. Biomed. Mater. Res. 2001, 54, 115-21.

31. Trudel, J.; Massia, S. P. Biomaterials 2002, 23, 3299-3307.

32. Hahn, S. K.; Park, J. K.; Tomimatsu, T.; Shimoboji, T. Int. J. Biol. Macromol. 2007, 40, 374-380.

33. Park, Y. D.; Tirelli, N.; Hubbell, J. A. Biomaterials 2003, 24, 893-900.

34. Anseth, K. S.; Burdick, J. A. MRS Bull. 2002, 27, 130-136.

35. Wang, D.-a.; Elisseeff, J. H. Encycl. Biomater. Biomed. Eng. 2004, 2, 1212-1225.

36. Shu, X. Z.; Ghosh, K.; Liu, Y.; Palumbo, F. S.; Luo, Y.; Clark, R. A.; Prestwich, G. D. J. Biomed. Mater. Res., Part A 2004, 68A, 365-375.

37. Marklein, R. A.; Burdick, J. A. Soft Matter 2010, 6, 136-143.

38. Destaing, O.; Planus, E.; Bouvard, D.; Oddou, C.; Badowski, C.; Bossy, V.; Raducanu, A.; Fourcade, B.; Albiges-Rizo, C.; Block, M. R. Mol. Biol. Cell 2010, 21, 4108-4119.

39. Fassler, R.; Pfaff, M.; Murphy, J.; Noegel, A. A.; Johansson, S.; Timpl, R.; Albrecht, R. J Cell Biol 1995, 128, 979-88.

40. Mansukhani, A.; Bellosta, P.; Sahni, M.; Basilico, C. J Cell Biol 2000, 149, 1297-308.

41. Bouvard, D.; Aszodi, A.; Kostka, G.; Block, M. R.; Albiges-Rizo, C.; Fassler, R. Development 2007, 134, 2615-25.

42. Bencherif, S. A.; Srinivasan, A.; Jiang, A.; Hollinger, J. O.; Matyjaszewski, K.; Washburn, N. R. Polym. Prepr. (Am. Chem. Soc., Div. Polym. Chem.) 2008, 49, 576-577.

43. Bryant, S. J.; Nuttelman, C. R.; Anseth, K. S. J. Biomater. Sci., Polym. Ed. 2000, 11, 439-457.

44. Kavanagh, G. M.; Ross-Murphy, S. B. Prog. Polym. Sci. 1998, 23, 533-562.

45. Bonino, C. A.; Samorezov, J. E.; Jeon, O.; Alsberg, E.; Khan, S. A. Soft Matter 2011, 7, 1151011517.

46. Flory, P. J., Principles of Polymer Chemistry. 1953; p 672 pp.

47. Lee, M. H.; Boettiger, D.; Composto, R. J. Biomacromolecules 2008, 9, 2315-2321.

48. Berrier, A. L.; Yamada, K. M. J. Cell. Physiol. 2007, 213, 565-573.

49. Zhang, X.; Jiang, G.; Cai, Y.; Monkley, S. J.; Critchley, D. R.; Sheetz, M. P. Nat. Cell Biol. 2008, 10, 1062-1068. 
Figure 1. In situ photorheometric measurement of hydrogel formation from methacrylate modified-HA: effect of reaction parameters on photogelation of the macromer $\mathbf{2 b}$ at a concentration of $15 \mathrm{~g} / \mathrm{L}$ in $\mathrm{PBS}$. The G' and G', curves are represented by black and grey lines, respectively, and the black and grey arrows indicate the crossover of the $G^{\prime}$ and G' moduli. A) Effect of photoinitiator concentration (\%, w/w): $0.2(-), 0.1(--), 0.05 \%(-\dashv, 0.025(\cdots \cdots \cdots) ; 0.01(-\cdots-)$; B) effect of power of light used for irradiation $\left(\mathrm{mW} / \mathrm{cm}^{2}\right): 144(-), 50(--), 15\left(-7\right.$. As the loss modulus, $\mathrm{G}^{\prime \prime}$, increased negligibly for all hydrogels, some of the G', curves are superposed.

Figure 2. Effect of time of irradiation and macromer concentration on the storage modulus of hydrogels prepared from HA-MA (A) 2a and (B) $2 \mathbf{b}$.

Figure 3. Effect of the degree of methacrylation on the mechanical properties of HA hydrogels prepared from solutions of macromers at a concentration of $15 \mathrm{~g} / \mathrm{L}$.

Figure 4. Storage modulus of hydrogels made of methacrylated HA $\mathbf{2 a}(\mathbf{\Delta}) \mathbf{2 b}(\mathbf{\square}), \mathbf{2 c}(\bullet)$ and $\mathbf{1 b}(\bigcirc)$ as a function of MA concentration $\left(C_{M A}\right)$.

Figure 5. Cell attachment and spreading on methacrylated HA hydrogels as a function of the G' values. Upper panel: phase contrast observations carried out on living cells with a Zeiss 100M Axiovert microscope equipped with a plan 10X objective (N.A 0.25). Cell Lower panels: cell spreading quantification. After cell fixation with paraformaldehyde, cells were labeled with Vybrant ${ }^{\mathrm{TM}}$ DIL lipophilic tracer. Observations of the fluorescent cells were carried out with an Olympus Provis 70 epifluorescent microscope equipped with a Plan NeoFluar 20X objective (N.A. 0.50). The images threshold value was adjusted to fit the cells limits and the projected cell areas were determined with Metamorph software. Statistical analyses and box plots were performed with the R software $(n=60)$. The bottom and top of the box are the $25^{\text {th }}$ and $75^{\text {th }}$ percentile (the lower and upper quartiles, respectively), and the band near the middle of the box is the $50^{\text {th }}$ percentile (median). The ends of the whiskers represent the lowest datum still within 1.5 Inter Quantile Range of the lower quartile, and the highest datum still within 1.5 Inter Quantile Range of the upper quartile. Bar is $40 \mu \mathrm{m}$. 
Figure 6. Effect of blocking antibodies rose against CD44 and RHAMM on primary osteoblasts spreading on HA methacrylate gels. The cells were pre-incubated for one hour at $4^{\circ} \mathrm{C}$ with the antibodies at the concentration of $30 \mu \mathrm{g} / \mathrm{mL}$ and seeded on the hydrogels with the antibodies. Culture was performed overnight under classical conditions, i.e. at $37^{\circ} \mathrm{C}$ in a humidified $5 \% \mathrm{CO}_{2}$ atmosphere. After cell fixation with paraformaldehyde, cells were labeled with Vybrant ${ }^{\mathrm{TM}}$ DIL lipophilic tracer. Observations of the fluorescent cells on 3 independent observation fields for each experimental conditions, were carried out with an Olympus Provis 70 epifluorescent microscope equipped with a Plan NeoFluar 20X objective (N.A. 0.50). Bar is $50 \mu \mathrm{m}$. 
Table 1. Reaction conditions for the modification of HA with methacrylate groups through the hydroxyl functions.

\begin{tabular}{cccccc}
\hline Reaction $^{\mathrm{a}}$ & Sample & AMA $^{\mathrm{b}}$ & \multicolumn{2}{c}{$\begin{array}{c}\text { Solvent } \\
(\text { Vol \%) }\end{array}$} & DM \\
\cline { 3 - 4 } & & & Water & DMF & \\
\hline 1 & $\mathbf{1 a}$ & 2 & 100 & 0 & 0.10 \\
2 & $\mathbf{1 b}$ & 20 & 100 & 0 & 0.20 \\
3 & $\mathbf{2 a}$ & 0.5 & 50 & 50 & 0.12 \\
4 & $\mathbf{2 b}$ & 1 & 50 & 50 & 0.20 \\
5 & $\mathbf{2 c}$ & 2 & 50 & 50 & 0.28 \\
6 & $\mathbf{2 d}$ & 3 & 50 & 50 & 0.49
\end{tabular}

${ }^{\mathrm{a}}$ All reactions were carried out at $4{ }^{\circ} \mathrm{C}$ during $16 \mathrm{~h}$; they were performed in duplicate to ensure reproducibility; ${ }^{\mathrm{b}}$ number of molar equivalents with respect to the HA repeating unit 
A)

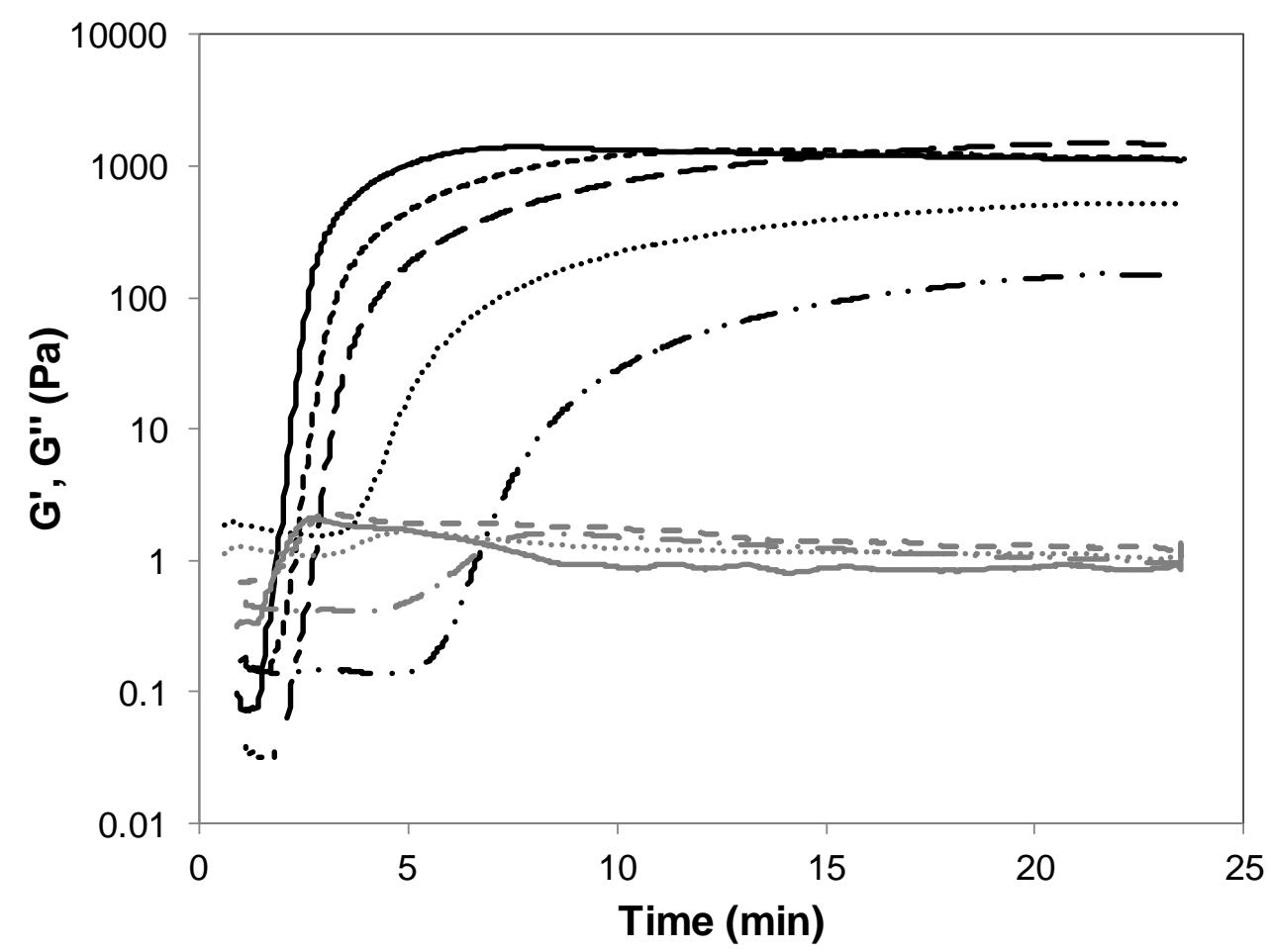

B)

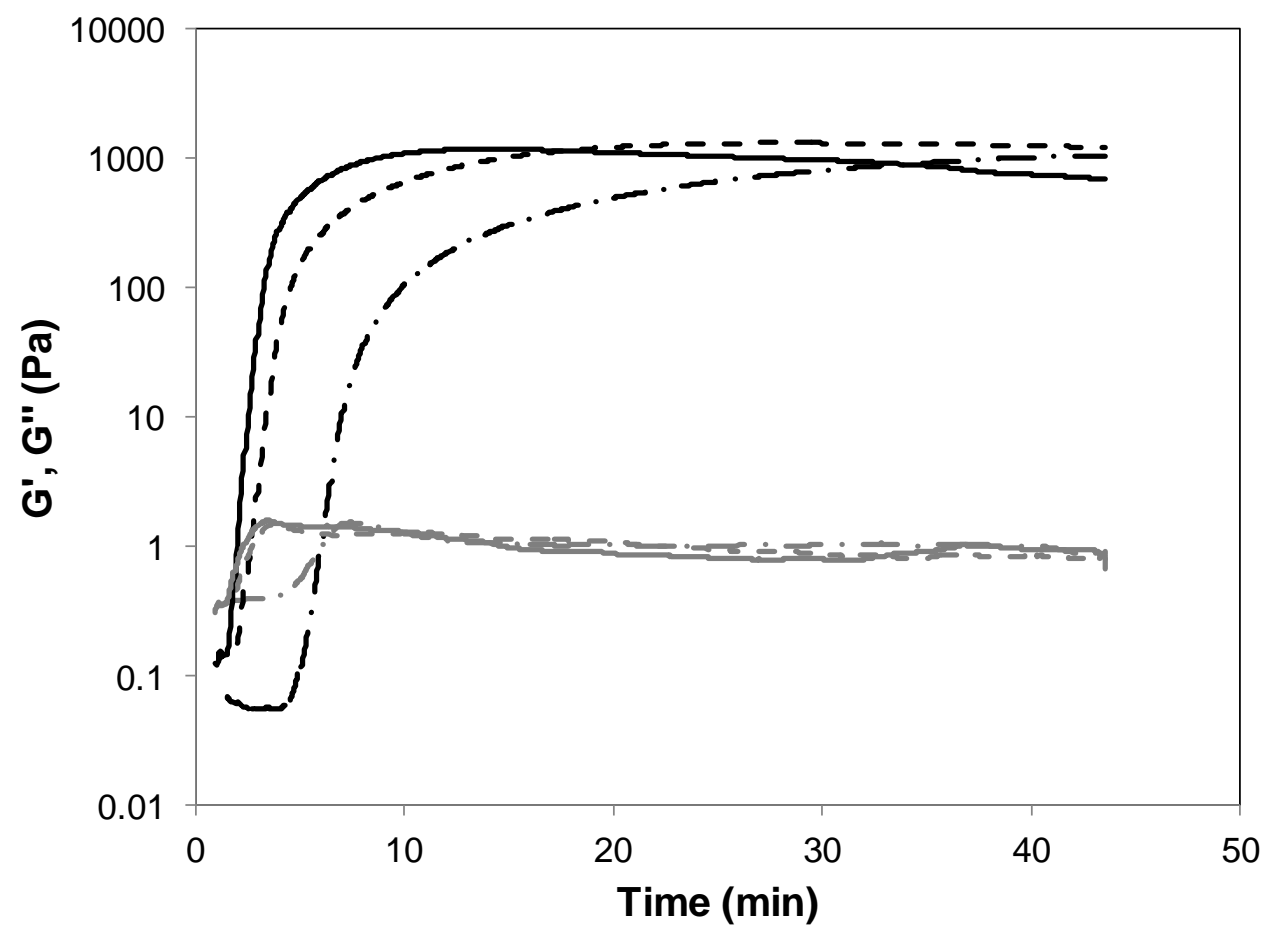

Figure 1 
A)

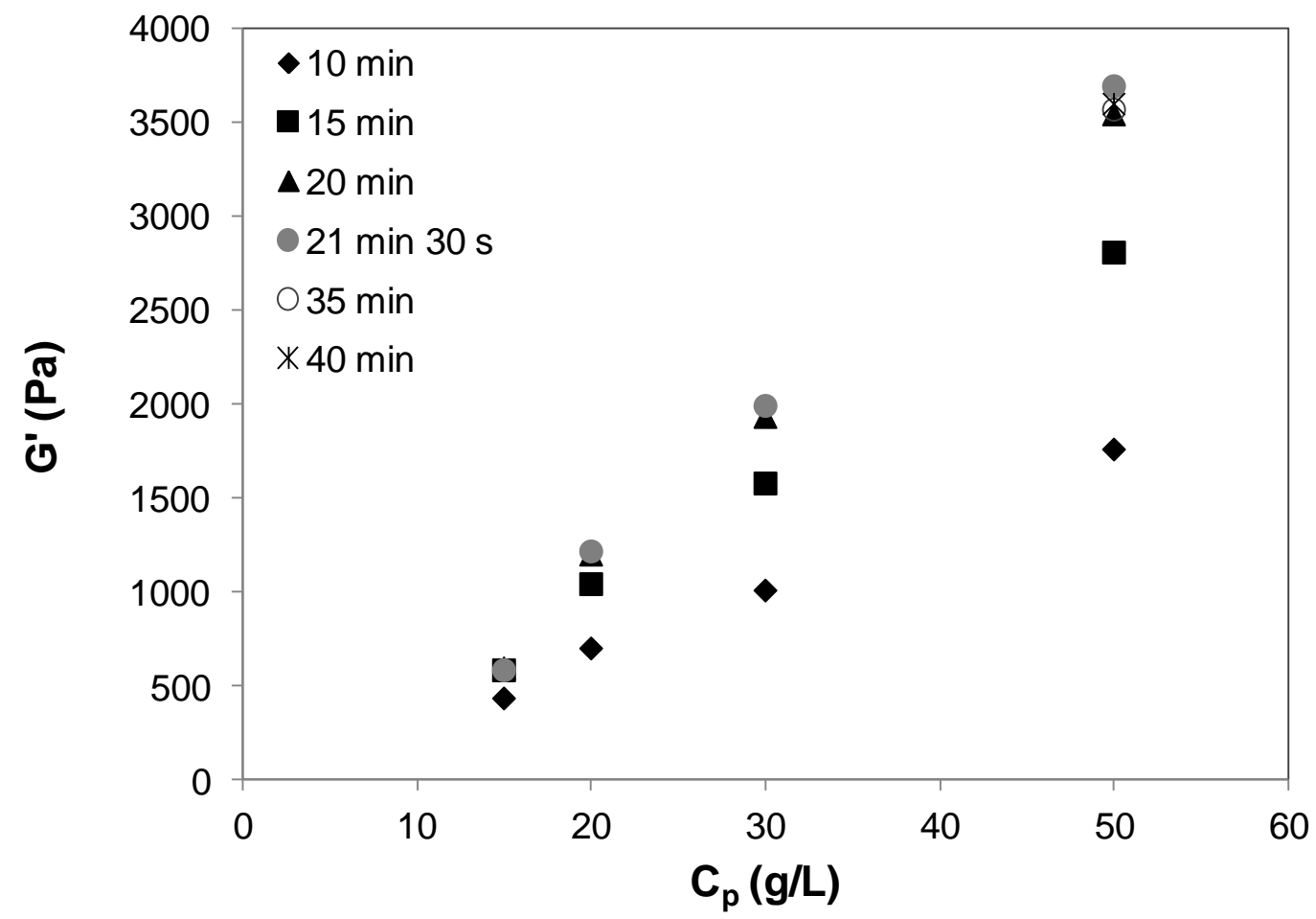

B)

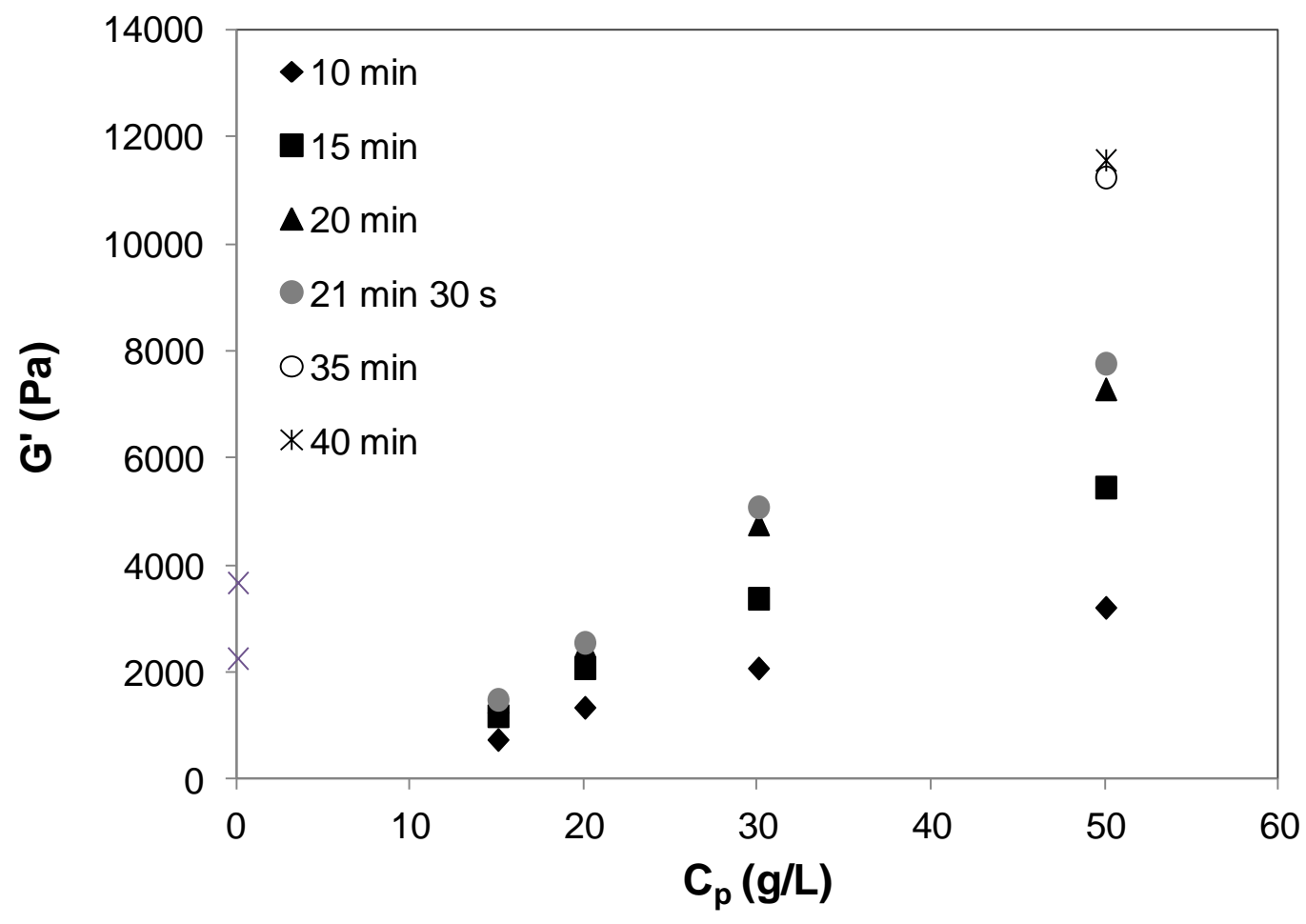


Figure 2

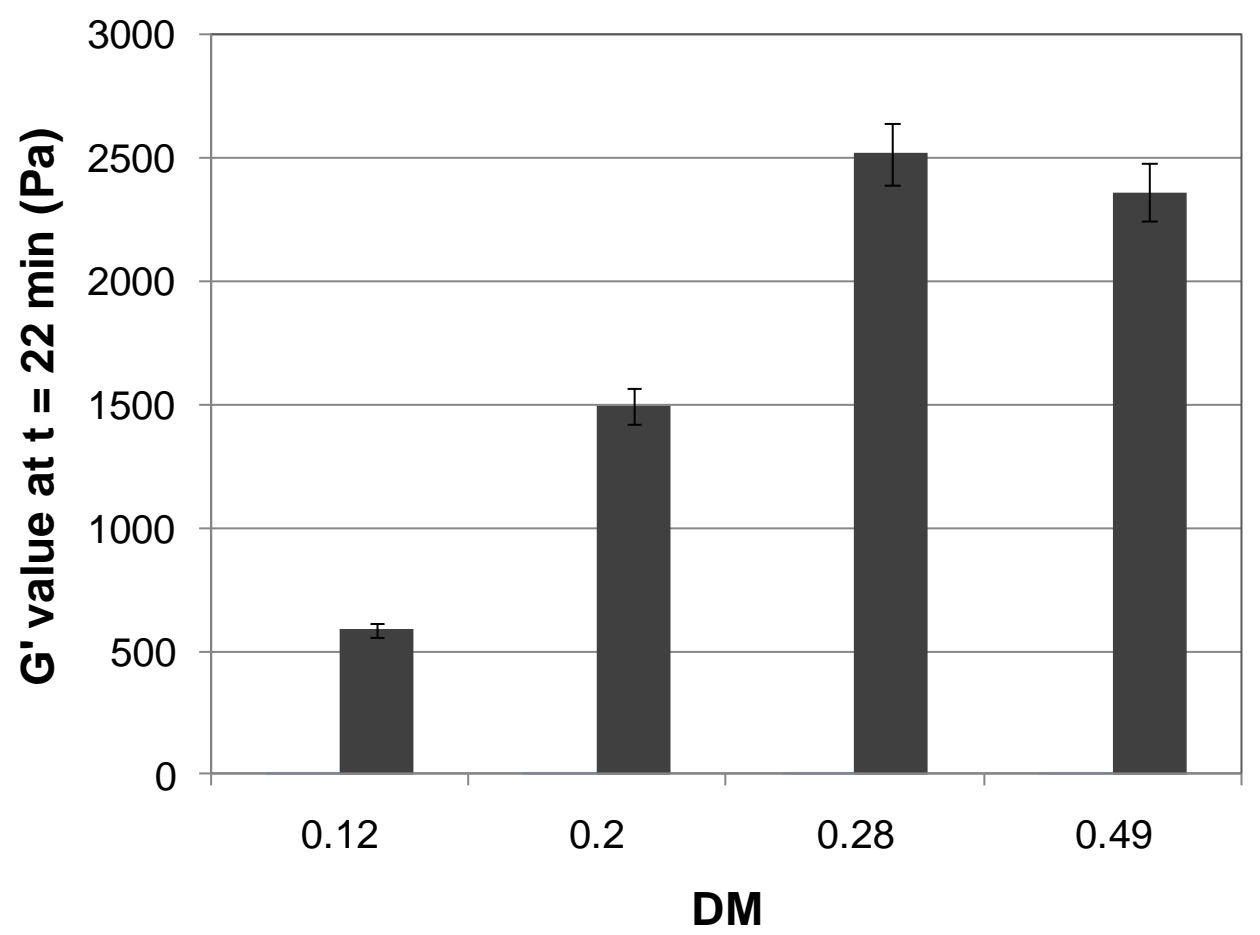

Figure 3 


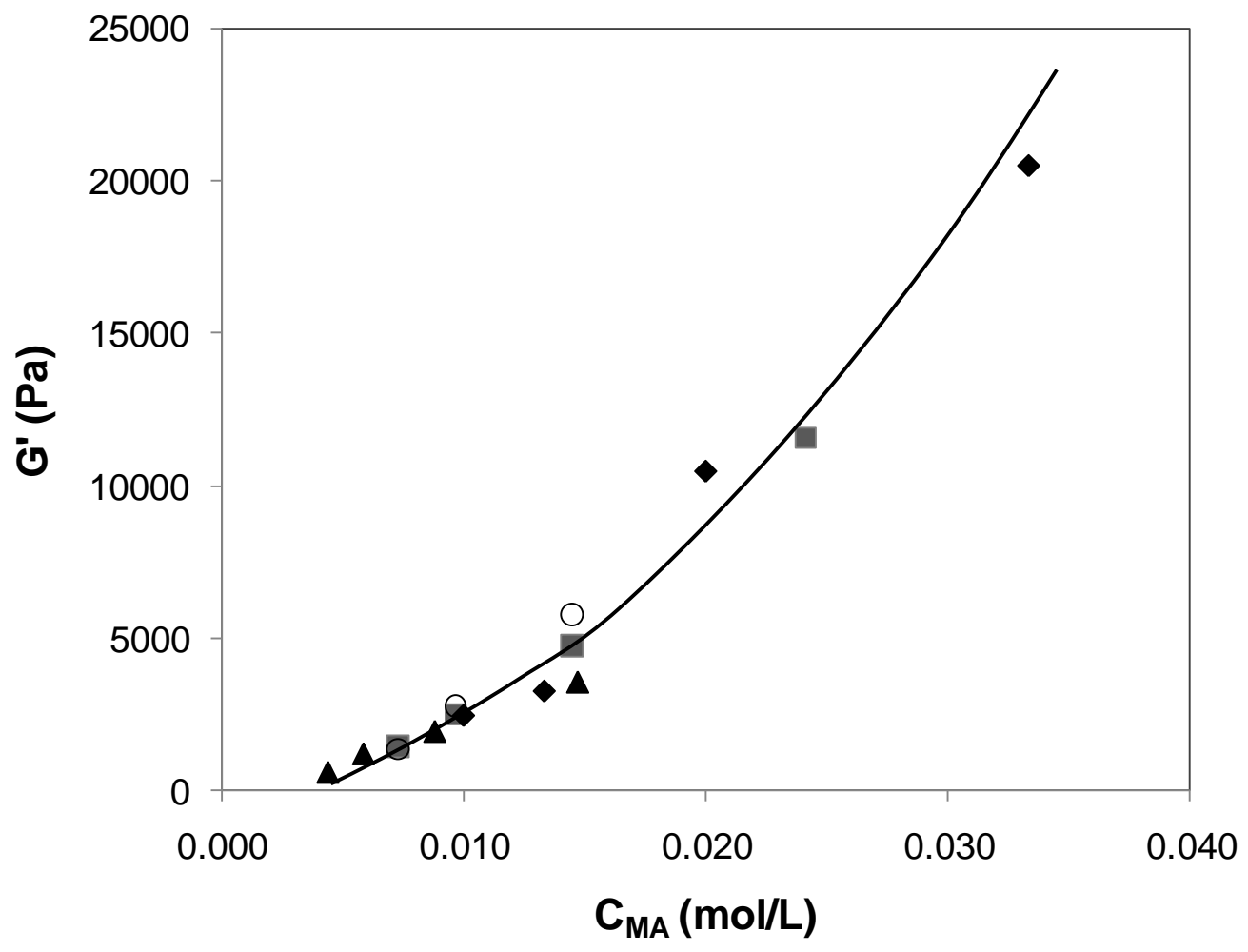

Figure 4 

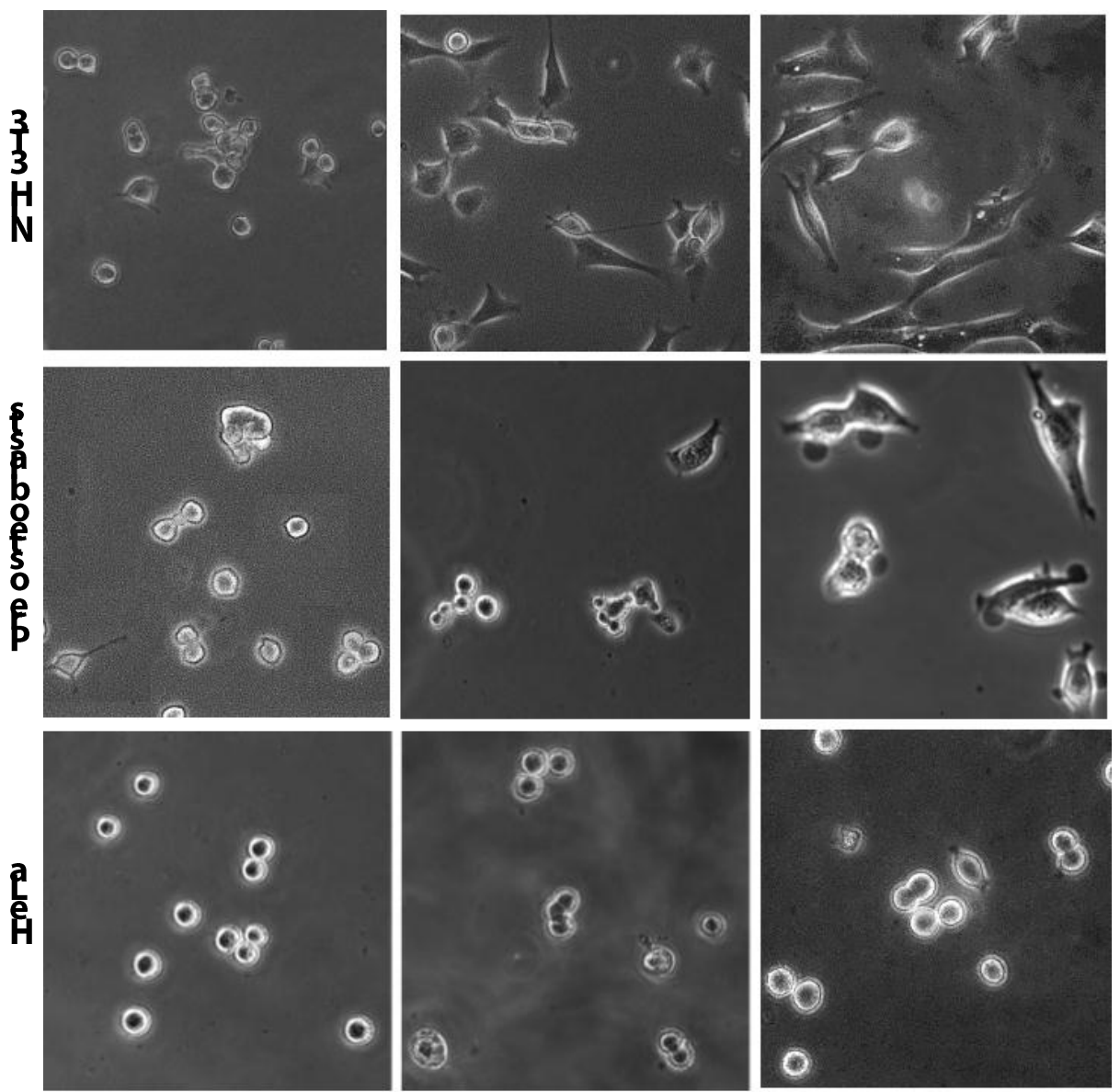

600

2500

17000

Storage Modulus (Pa)
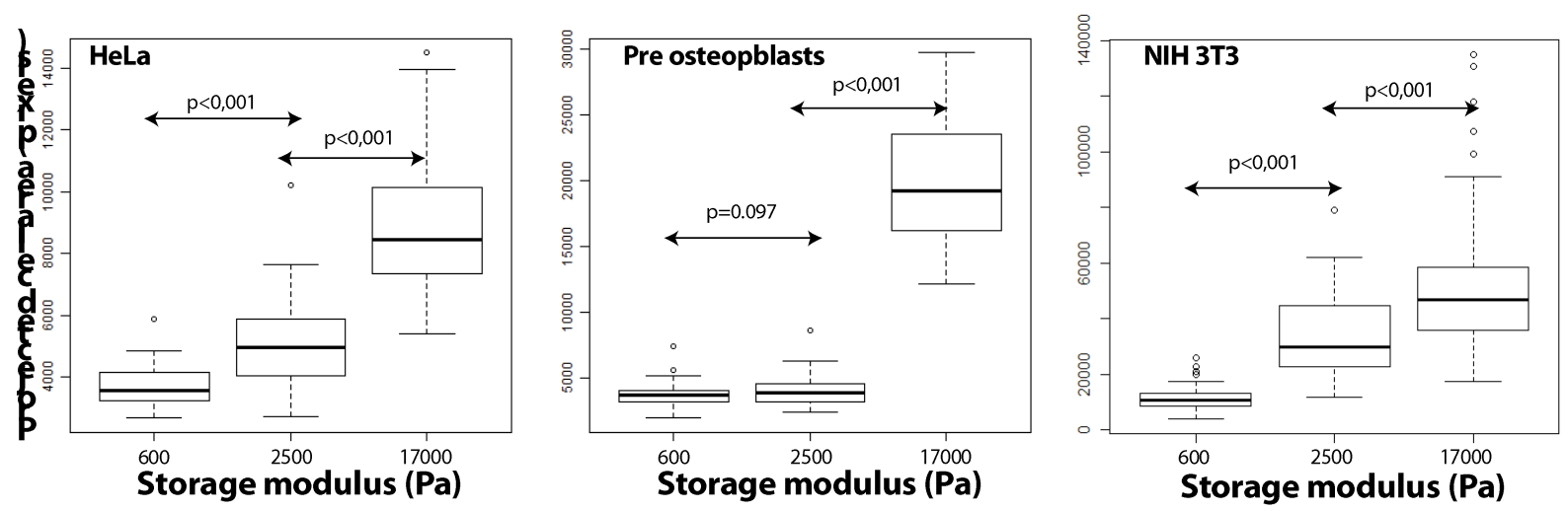

Figure 5 

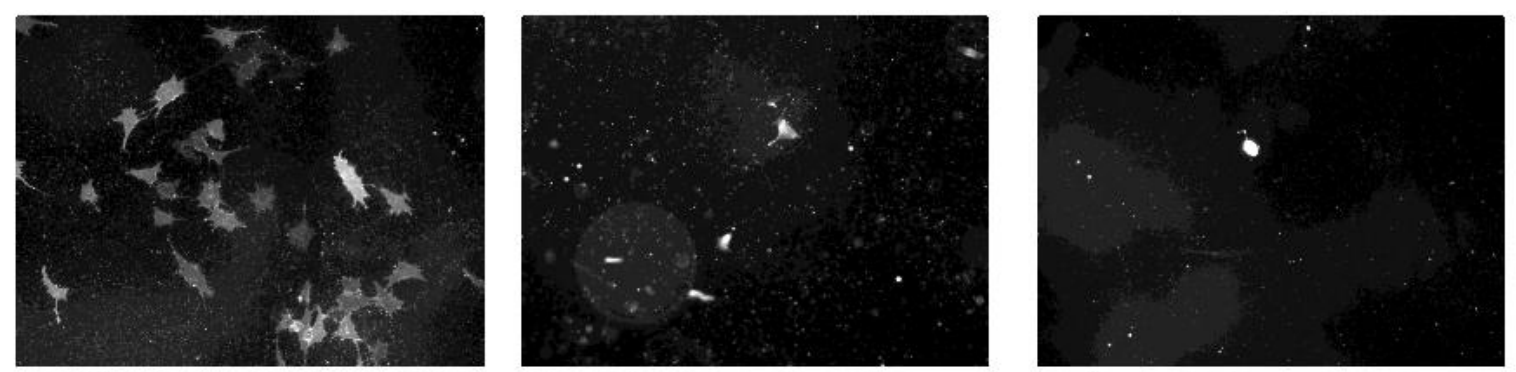

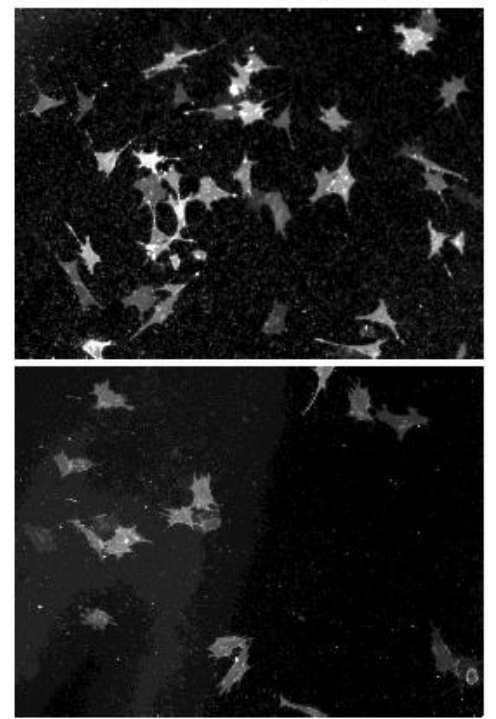

Control

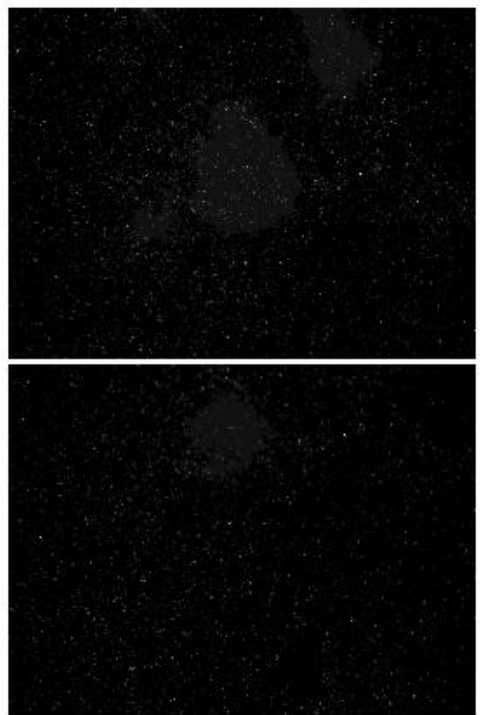

Anti CD44

$30 \mu \mathrm{g} / \mathrm{mL}$

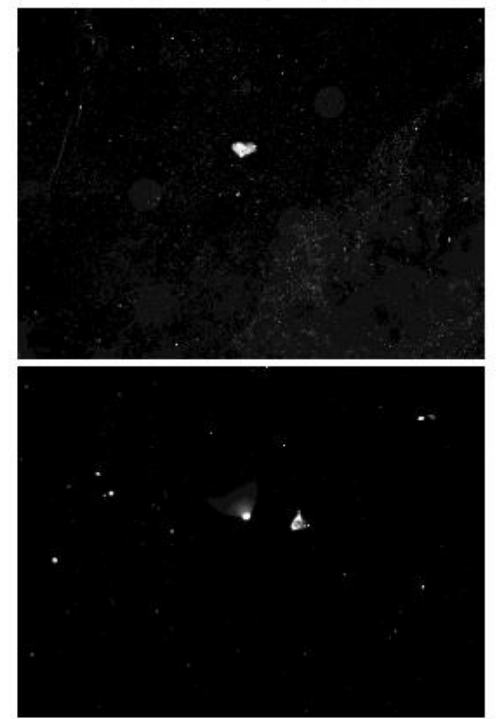

Anti RHAMM

$30 \mu \mathrm{g} / \mathrm{mL}$

Figure 6 